\title{
ESCOLA E EDUCAR NA FRONTEIRA: ATOS DO ESTADO SE [DES]FAZENDO EM SEUS LIMITES'
}

\author{
REgiNA CoEli MACHADO E Silva \\ Professora da Unila e da Unioeste \\ coeli.machado@yahoo.com.br
}

\section{O lugar da escola na fronteira}

O lugar da escola em uma cidade localizada em fronteiras nacionais como análogo ao papel ideal, mesmo controverso ${ }^{2}$, da Organização das Nações Unidas (ONU) foi sugerido por uma professora do ensino fundamental para acentuar o próprio entendimento de que a escola não é um mundo a parte, um mundo paralelo. Pensar a escola como uma organização que idealmente transcende limites nacionais ao mediar relacionamentos e estabelecer comprometimentos entre atores sociais diferentemente posicionados em contextos fronteiriços é uma das formas pelas quais podemos compreender a escola articulada às relações entre estado-nação e os modos de existência fronteiriços. Estado-nação e fronteiras não são conceitos abstratos e empiricamente separados; são coconstitutivos. Estados-nações se instituem e, no mesmo movimento, instituem suas fronteiras.

Neste capítulo, deter-me-ei nas tensões coconstitutivas circunscritas nos modos de existência fronteiriços dos quais as escolas, como várias outras instituições, são parte. Enfoco particularmente uma escola pública de ensino básico e fundamental em Foz

1 Os dados utilizados neste capítulo são de pesquisa em andamento, do projeto intitulado "Em escola de fronteira: autoentendimentos compartilhados e segredo público", parte das minhas atividades como pesquisadora produtividade do CNPq nível 2.

2 Trata-se do ideal de articular modos de vida fronteiriços com demandas institucionais da Escola, nacionais, por meio da mediação de conflitos e ações para manter a participação das crianças no sistema escolar. É análogo ao papel de mediar conflitos para a paz na ONU, muitas vezes inoperante pelos longos impasses e pelas relações de poder desiguais entre os países. 
do Iguaçu $u^{3}$, no Paraná, que objetiva, ao mesmo tempo, a presença convencional do estado-nação brasileiro e o modo de existência fronteiriço, tornando manifestas as ambiguidades das quais é parte inseparável. Busco evidenciar essas ambiguidades nas tensões coconstituvas do estado-nação na peculiaridade das atividades de milhares de pessoas que lidam com a ilegalidade ao transportarem mercadorias de Ciudad del Este (Paraguai) para Foz do Iguaçu (Brasil), ilegalidade gerada pelos grandes volumes, pela evasão de pagamentos de impostos, e/ou por tratar de mercadorias proibidas como produtos falsificados, drogas, armas etc.

Argumento que as tensões encontradas na Escola do lado brasileiro dessa fronteira são indissociáveis do modo de vida nesse contexto, posto que as fronteiras instáveis do estado-nação são constantemente refeitas e (des)feitas nos próprios termos dos envolvidos - nas relações entre diferentes crianças, professores, pais, adultos e gestores dos serviços públicos. Tais tensões restabelecem e recompõem formas de participação social e, no mesmo movimento, podem afetar a legitimidade do Estado, dele distanciando-se e aproximando-se, seja radicalizando e relativizando (objeto deste capítulo), seja transpondo ${ }^{4}$ ou tentando sobrepor as fronteiras do estado-nação, a exemplo do Programa Escolas Interculturais de Fronteira (PEIF) $)^{5}$, recentemente desativado.

3 Doravante será identificada como Escola e o bairro onde está localizada como Bairro. Foz do Iguaçu é conhecida como destino turístico internacional e, por meio do noticiário nacional, pela divulgação recorrente de apreensão de grande volume de mercadorias, drogas e armas contrabandeados.

4 Como no fluxo intenso e diário de estudantes de medicina brasileiros entre Ciudad del Este e Foz do Iguaçu. Grande parte vem de todo o Brasil, reside em Foz do Iguaçu e atravessa a fronteira todos os dias Webber, 2018. Há também muitos estudantes do ensino médio, filhos de coreanos, chineses e árabes que residem em Ciudad del Este e frequentam escolas em Foz do Iguaçu.

5 O PEIF foi criado no âmbito do Mercado Comum do Sul (Mercosul), de 2012, e aplicado em uma escola na Argentina (Puerto Iguazu) e em outra no Brasil (Foz do Iguaçu). A implantação do PEIF é paradoxal. A proposta de ensino bilíngue tende a aprofundar as diferenças de práticas linguísticas e encontra dificuldades pela ritualização da passagem da fronteira entre os países. Em relação ao tema, consultar Flores (2012). 
Para circunscrever melhor o enquadramento dado a este capítulo, é importante fazer algumas considerações. A primeira refere-se às problematizações sobre a escola (e correlativamente à educação) em suas inter-relações nos contextos sociais. Elas nos remetem a desafios teóricos de grande abrangência temática com contrastantes abordagens analíticas internas em campos disciplinares diversos e não serão objeto de atenção. Tomo como pressuposto que a Escola em foco (como qualquer outra) é inseparável do contexto social. Como definiu Milstein, as escolas "são espaços sociais diferenciados e ao mesmo tempo interrelacionados de múltiplas maneiras com os grupos, práticas e conflitos da sociedade local e global" (Milstein, 2009, p. 36). O contexto está na escola, perpassado tanto pelas políticas públicas brasileiras para a educação quanto pelas tensões sociais e políticas vividas por todos os agentes que dela participam, desde os diferentes agentes escolares nas relações com seus alunos até os pais e adultos com quem convivem no Bairro onde a Escola se insere, como mostrarei à frente. $\mathrm{Na}$ Escola será possível acompanhar os modos pelos quais esses agentes, social e diferentemente posicionados, experimentam o contexto de fronteira geopolítica, materializando ou diluindo a intersecção entre estados-nações.

A segunda consideração refere-se às relações das instituições escolares com o tema do estado-nação, principalmente desde o século XIX, quando a educação primária se tornou obrigatória. Como enfatizou Pierre Bourdieu (2007), o sistema escolar é um dos meios de dominação e de manutenção da ordem social e simbólica, reproduzindo-as em suas diferenças e em suas desigualdades, ao mesmo tempo em que promove a unificação dessas ordens. Por ser una e múltipla, como dizia Émile Durkheim (1978), a educação escolar constitui fator fundamental na participação de um senso comum necessário à unificação de um estado-nação. Decorre daí a lógica de analisar a escola que (como parte do conjunto das instituições burocráticas, entre outras) que institui o estado por meio de controles disciplinares (Foucault, 1998), de ideias-valores (Dumont, 1995) e de relações de pertencimento e de identificação: falar a mesma língua, participar de um mesmo conjunto de cidadãos e habitar um mesmo território, por exemplo. A Escola na fronteira 
é parte desse sistema escolar que constrói, por meio da educação, o amálgama do estado-nação, ao mesmo tempo em que o relativiza por suas interações ativas no contexto local.

Este capítulo está organizado em partes delimitadas por níveis concêntricos de abrangência que convergem para o objetivo de evidenciar, na Escola, a articulação das ordens do estado-nação brasileiro com a distintividade do modo de existência fronteiriço. $\mathrm{Na}$ primeira parte, apresento os contextos convencionais que circunscrevem as relações entre estado-nação, fronteiras (geopolíticas e simbólicas) e educação, inclusive no Brasil. Procuro ressaltar o papel da educação escolar (e seu efeito de propagação da cultura erudita e letrada) na construção do estado-nação, situando-o teórica e historicamente, o que é também um meio de explicitação da abordagem analítica. Na segunda parte, apresento o contexto e o modo de vida fronteiriços nas tensões coconstitutivas do estado-nação, em Foz do Iguaçu, experimentado por pessoas que transportam mercadorias entre Ciudad del Este, Paraguai, e Foz do Iguaçu, Brasil. Na terceira, exploro essas tensões coconstitutivas no espaço físico da Escola, onde emergem diversas práticas e saberes que instituem o estado-nação, tanto radicalizando como relativizando seus limites.

\section{Contextos convencionais do estado-nação e educação}

Um esquivar-se contínuo emerge quando estudamos as mediações entre fronteiras nacionais e estado-nação. Se, por um lado, há um senso comum que caracteriza o estado-nação por critérios como língua, território comum e cultura; por outro, parece ser um dado trivial o fato de as fronteiras unirem e dividirem estados-nações, com limites ao movimento que podem criar, simultaneamente, razões para atravessá-los. Contudo, isso não significa sabermos, de modo imediato, como os limites são instituídos, relativizados ou radicalizados, demarcando com mais ou menos rigidez as interdições jurídico-políticas entre os diferentes grupos, nacionais, que os atravessam. Dependentes uma das outras, as demarcações entre estados nacionais e suas fronteiras são formas de objetivação histórica e social a serem verificadas e analisadas em cada situação empírica, pois os limites entre as fronteiras são móveis. Eles 
não estão apenas nas alfândegas de aeroportos, em pontes ou simplesmente em uma rua. São constantemente feitos e (re)feitos em suas tensões instituintes, de forma mais incisiva nas práticas e nos saberes de diversas instituições estatais controladoras e fiscalizadoras de impostos e de limites territoriais, ou de forma menos incisiva, mas não menos importante, nas instituições escolares públicas. Para abordar os modos de atualização dessas tensões instáveis e instituintes entre estado-nação e fronteiras na Escola, em Foz do Iguaçu, adoto uma orientação geral da Antropologia, abordando estado-nação, fronteiras e educação como categorias sociais e sociológicas próprias de experiências coletivas.

A ideia de nação (com seus limites) e as suas articulações em contextos convencionais vinculados à educação (de forma mais abrangente, como integração cultural e lógica no sentido durkheimiano, e de forma mais específica, como educação pública e vinculada ao estado) foram e são muito debatidas por autores sob diferentes perspectivas e áreas de conhecimento. Para destacar a relevância dessas inter-relações, menciono rapidamente algumas abordagens sem considerar diferenças analíticas e históricas entre elas. Algumas tematizam as formas abrangentes (escolares e não escolares) pelas quais nos tornamos membros da sociedade por meio da socialização e da transmissão de ideias-valores (Durkheim, 1978; Mead, 2017; Benedict, 1972; Bourdieu, 1996, 2007). Outras abarcam as consequências da alfabetização em massa, a exemplo de Benedict Anderson (2008), quando aborda o contexto da proliferação de jornais e outras publicações - o romance é uma delas. A leitura feita dessas publicações, em diferentes lugares e por pessoas que não se conhecem e nem se identificam, cria uma ligação simbólica e, no mesmo movimento, a nação como comunidade imaginada (como também o fazem os museus, os mapas e os censos). A importância do romance como forma cultural e veículo de ideias-valores para construir uma "estrutura de atitudes e referências" imperialistas que colocam em jogo a geografia e o poder em suas relações com as colônias foi estudada por Edward Said (2011), bem como por Doris Sommer (2004) que analisou os romances, "ficções de fundação", associados a instrumentos pedagógicos para induzir a posturas patrióticas e 
nacionalistas nos leitores de países latino-americanos $(2011)^{6}$. A importância das culturas eruditas para a constituição do estado-nação, apontada também por Ernst Gellner (1993), está intimamente ligada à constituição de um sistema educacional padronizado e público, delegado pelo estado nas sociedades industriais. Eric Hobsbawm igualmente cita, entre outros meios para a socialização política, a escolarização em escala nacional como uma "forma de estabelecer padrões comuns de comportamento e valores" (Hobsbawm, 1997, p. 301) e reunir indivíduos e famílias, sem relações pessoais, em estratificações sociais internas.

Das diferentes perspectivas de abordagens, o que emerge como uma variável comum a todos é que categorias como estado-nação, apesar de tenderem à universalização, dependem substantivamente de processos históricos e sociais a serem observados, razão pela qual devem ser submetidas às reflexões epistemológicas a respeito das condições que os produziram. Como sugeriu Marisa Peirano, na nação, está subsumido o estado, forma pela qual identificamos grande parte das sociedades recentes. Sob essa perspectiva, aproveito a sugestão feita por ela: "observar o estado em ato, a nação se fazendo" (Peirano, 2006, p. 136) ou se desfazendo. Essa fórmula nos permite acompanhar as tensões que instituem, radicalizando ou relativizando, as fronteiras do estado-nação nas práticas e nos saberes escolares.

Raciocínio homólogo se aplica à noção de fronteira, entendida como uma linha fictícia, porque construída pela "arbitrariedade" de processos classificatórios instáveis, que jamais se completarão. As linhas divisórias muitas vezes foram traçadas por decisões geopolíticas resultantes de longos processos históricos ou de conflitos bélicos (Hobsbawm, 1990), mas igualmente vividas e experimentadas em práticas e saberes de quem nelas vive. A "arbitrariedade" suposta na fronteira tem dois significados inseparáveis: é contingente (como reificação de uma abstração social) e obrigatória (pelo controle e pela fiscalização de pessoas e coisas que a supõem, com seus efeitos impactantes no cotidiano).

6 De maneira diversa, Dorfman (2008) analisou contos ficcionais da fronteira entre Brasil e Uruguai como chave analítica para compreender as práticas cotidianas da população fronteiriça, normalmente sigilosas. 
Um dos modos de perceber as tensões entre os atos do estado-nação em suas fronteiras e a vida das pessoas, em geral, é a observação dos rituais de passagem de um país ao outro. A experiência de atravessar fronteiras é, na existência subjetiva e coletiva, ao mesmo tempo, instituída (pela existência de regras e restrições) e instituinte (pela percepção do contraste na passagem) dos estados-nações. $\mathrm{O}$ ato de deslocar-se, independente das motivações das pessoas, é um dos modos pelos quais o pertencimento (nacional) se realiza, paradoxalmente, na travessia de um país a outro (Silva, 2013) ${ }^{7}$.

Mapas estabelecendo limites, demarcando espaços; paisagens e monumentos materializando símbolos das nações; e documentos pessoais, ao vincularem cada um a uma nacionalidade, explicitam indubitavelmente a presença do estado-nação na experiência coletiva e individual. Essa presença, instituída e instituinte, está nas instituições burocráticas desde as mais visíveis, como as encarregadas da segurança nacional e pública, até as que regulam a vida jurídica, econômica, político-ideológica e cultural, incluindo aí a educação. A educação, como disse Bourdieu (2014), é um tema obrigatório na compreensão do estado-nação, não só porque ele a institui, mas porque o sistema escolar também o faz. Estudando a construção da nação na França, Bourdieu afirma que "o Estado faz a nação: ele a faz pela escola” (Bourdieu, 2014, p. 622). O sistema escolar, para esse autor, é uma das mais eficazes fontes de integração social e lógica (isto é, cultural). Categorias de percepção, de pensamento e de ação comuns tornam-se um "produto do cérebro" por meio um trabalho de inculcação realizado nos manuais escolares, em especial os manuais de história (Bourdieu, 2014, p. 622).

Tal papel da educação possibilitou que ela se convertesse em função cívica, e a função cívica se identificasse com a realização do ideal do estado nacional, sobretudo no final do século XIX, Idade de Ouro do estado-nação, conforme mencionou Hobsbawm (1990).

7 Para transitar de um país a outro, é necessária a apresentação pública e oficial de si, sob a forma de um documento de identidade, a ser apresentado aos "guardiões" das fronteiras, ou seja, aos agentes da imigração, da defesa e da segurança. A carteira de identidade (ou passaporte) é também o suporte do estado civil ou o conjunto de propriedades (nacionalidade, sexo, idade, filiação etc.) que vincula cada um juridicamente a um estado-nação. 
Houve a campanha europeia para manutenção da educação pelo estado em termos nacionalistas, diminuindo o predomínio do cosmopolitismo individualista do século XVIII, que buscava o ideal de perfectibilidade iluminista de uma humanidade progressivamente esclarecida, a ser obtida por meio da educação privada, clássica, humanista e religiosa. Um efeito de importância incalculável dessa mudança foi que "[...] o cosmopolitismo cedeu o lugar ao nacionalismo. Formar o cidadão, e não o ‘homem', tornou-se a meta da educação.” (Dewey, 2010, p. 101) ${ }^{8}$. A educação tornou-se pública, isto é, muitas vezes oferecida pelo estado, por ele controlada e reconhecida.

O Brasil acompanhou esse movimento histórico; especialmente a partir do Estado Novo, a educação foi politizada como questão nacional, embora o vínculo da educação com o estado seja bem anterior, a exemplo da reforma pombalina durante o período colonial (Maxwell, 1996). Na década de 1930, a educação tornou-se parte inseparável do projeto de construção do estado-nação, quando foi criado o Ministério da Educação e Saúde Pública no governo de Getúlio Vargas. Nesse período, por exemplo, foi implementada uma intensa campanha de nacionalização para erradicar influências estrangeiras dos imigrantes alemães, mas também dos poloneses e dos italianos no Rio Grande do Sul, Santa Catarina e Paraná. Essa campanha teve como "primeiro ato" estatal, como escreveu Seyferth, "proibir o sistema de ensino em língua estrangeira: a nova legislação obrigou as chamadas 'escolas estrangeiras' a modificar seus currículos e a dispensar os professores 'desnacionalizados'; as que não conseguiram (ou não quiseram) cumprir a lei foram fechadas" (Seyferth, 1997, p. 97). A intervenção fez com que desaparecesse a imprensa étnica, juntamente com as tentativas de nacionalizar o ensino e de impor a língua portuguesa como critério de nacionalidade ${ }^{9}$.

8 Dewey atribui esse efeito à filosofia germânica e às consequências históricas das conquistas napoleônicas, especialmente na Alemanha. Os estados germânicos pressentiram que a atenção sistemática voltada para a educação era o melhor meio de recuperar e manter a integridade e a soberania políticas, desenvolvendo um amplo e sólido sistema de educação pública.

9 A educação escolar como um dos lugares privilegiados da produção do nacionalismo estatal na Era Vargas, no Sul e Sudeste, é tema de uma coletânea intitulada Uma gota amarga, organizada por Claudemir Qua- 
A principal preocupação do Estado Novo na fronteira entre Brasil, Paraguai e Argentina era a influência argentina (Lopes, $2004^{10}$ apud Paiva, 2016) de modo que a prefeitura de Foz do Iguaçu buscou promover uma administração que afirmasse a ocupação do território brasileiro por meio do uso da moeda nacional e da utilização da língua oficial (Paiva, 2016) em documentos, anúncios comerciais ou avisos.

O controle público do ensino em todo o território brasileiro tem sido, desde então, concomitante à afirmação da nação e ao interesse do estado, obviamente com objetivos, ênfases e políticas próprios dos regimes políticos em vigor ${ }^{11}$, como o período da ditadura militar. Esse regime instituiu, em 1969, a disciplina obrigatória Educação Moral e Cívica em todos os níveis do ensino, para promover o culto à Pátria, seus símbolos, tradições e instituições como meio de exaltar o nacionalismo.

Com a reabertura democrática no Brasil e a Constituição Federal promulgada em 1988, além da pretensão de ampliar os direitos à população, houve a expansão do ensino obrigatório e a intenção de democratizar a gestão das instituições escolares. A educação tornou-se uma prioridade do estado-nação, visível no slogan oficial do governo, "Brasil, Pátria Educadora”. Essa prioridade deu-se de modo ambíguo, pois juntamente com os avanços para a educação inclusiva e para democratização do acesso escolar, também se estabeleceram "parcerias" com os setores público e privado para um projeto mais amplo de reconstituição da educação pública no âmbito do setor de serviços (Souza, 2001, 2013) ${ }^{12}$.

dros, 2014. O título refere-se às práticas nacionalizadores do estado brasileiro que "azedava" o trabalho docente nas colônias.

10 LOPES, S. O Território Federal do Iguaçu no contexto da "Marcha para Oeste": Bases para a ocupação e colonização das regiões Oeste e Sudoeste do Paraná. In: III Seminário do Centro de Ciências Sociais Aplicadas Cascavel, Cascavel, 2004.

11 Para uma visão geral dos diferentes vínculos entre os regimes políticos e as políticas escolares até os anos recentes consultar Souza (2015).

12 Houve críticas às políticas e a programas para a educação nesse último período, especificamente ao Plano Nacional de Educação para o decênio 2011-2020. Uma delas era de que, embora nacional, as propostas contidas envolveram responsabilidades atribuídas a municípios e estados, que já eram parte da estrutura de organização do sistema educacional no país. 
Tais programas na educação estavam vinculados a uma política macroeconômica, direcionada, também, à grande parte da população em situação de sobrevivência abaixo da linha da pobreza ou em um nível elementar de sobrevivência e consumo. A realização de políticas compensatórias para a baixa distribuição de renda ${ }^{13}$, como o Programa Bolsa Família, articula-se com as da educação em suas capilaridades, aliado ao sistema judiciário de atenção às crianças e aos adolescentes, como apresentarei à frente. Em termos de financiamento, registra-se a criação do Fundo de Manutenção e Desenvolvimento da Educação Básica e de Valorização dos Profissionais da Educação (Fundeb) e a fixação do piso nacional de pagamento, muitíssimo baixo, para o magistério da educação básica, uma conquista histórica do magistério nacional (Oliveira, 2011).

A proibição do ensino e de escolas estrangeiras no Sul do país, a obrigatoriedade do ensino da língua oficial e de disciplinas próprias para "cultivar" o sentimento de nacionalismo durante a ditadura, a criação de programas para melhorias dos índices de avaliação e de "qualidade" da educação nacional nos últimos anos são atos que instituem o estado-nação por meio do sistema escolar. Com o papel de integração lógica e cultural, o sistema escolar, em um mesmo movimento, demarca os limites do estado de fora para dentro (unidade do estado nacional) e de dentro para fora, contrastado com outros estados-nações, movimento mais visível particularmente nas fronteiras. Cotidianamente o estado é feito por meio de práticas e saberes que, de forma incansável, o demarcam, seja pelo ensino da língua oficial e das disciplinas, seja pela ritualização que vivifica o estado-nação em datas pátrias ou símbolos como a bandeira e o hino nacional, seja na capilaridade dos programas governamentais da educação, visível em seus processos de gerenciamento, controle.

É a existência da educação nacional que compõe o horizonte abrangente tanto de similaridade quanto de tensão para as escolas em contextos fronteiriços. Elas necessariamente incorporam e, por vezes, modificam e subvertem inventivamente essa educação nacional em suas práticas e saberes cotidianos. Expressando de

13 Outras ações envolviam acesso diferenciado e intenso ao crédito para aquisição de casa própria e a bens de consumo, a programas de acesso à energia etc. 
um modo inverso em suas articulações, a educação distintiva dos modos de existência fronteiriços relativiza, no mesmo movimento, o alcance generalizante pretendido pela educação nacional.

É o que quero mostrar na Escola na fronteira em Foz do Iguaçu. Radicalizar a objetivação do estado-nação, nessa Escola, como será detalhado a frente, é incorporar ativamente os atos do estado em seus programas para todo o território nacional. Relativizar é se engajar em relacionamentos e interlocuções do contexto fronteiriço onde está situada, contexto que apresento rapidamente a seguir.

\section{Escola em contexto fronteiriço}

Nas três fronteiras entre Brasil, Paraguai e Argentina, nossa familiaridade com mapas para visualização e orientação no espaço parece não deixar dúvidas sobre as fronteiras que demarcam os diferentes estados-nações (figura 1). Éassim que “vemos” o rio Paraná "separar" o Paraguai do Brasil; o rio Iguaçu desaguando no Paraná, separando o Brasil da Argentina, e, ao mesmo tempo demarcando, sob a forma de um “T”, os três países. A máxima objetivação desses estados-nações está nesse poder de nomeação da linguagem e no delineamento gráfico que os instituem, quando os convenciona e arbitrariamente traça linhas tão eficazes que identificamos o solo aos nossos pés por essas "realidades" não colocadas sob qualquer dúvida: estando em Foz do Iguaçu, dizemos que vamos ao Paraguai e, estando em Ciudad del Este ou Puerto Iguazu, do outro lado dos rios, nos referimos ao lado oposto como Brasil ou "lá no Brasil", como se estivéssemos a milhares de metros de distância. Dos prodigiosos simbolismos aí gerados, o mais instigante é o que demarca e multiplica alteridades, instituindo um nós em relação a outros, brasileiros, paraguaios e argentinos. Das linhas imaginárias que claramente separam simbolismos e alteridades nos mapas, há dois elementos comuns sobre os quais se impõem as divisões: as Cataratas do Iguaçu, entre Argentina e Brasil; e a usina binacional Itaipu, entre Paraguai e Brasil, no rio Paraná que, em suas unicidades, reintroduzem novamente os limites: nas cataratas, únicas, há as Cataratas do lado argentino e as do lado brasileiro; na usina, única como edificação, há a identificação da barragem (e tudo 
mais, do prédio administrativo, da casa de máquinas e das vias internas de acesso) como margem direita, Paraguai, e esquerda, Brasil, a tal ponto que, no interior do único edifício, os funcionários de Itaipu, paraguaios e brasileiros, referem-se aos colegas que "trabalham na margem direita" ou "na margem esquerda". Para o senso comum, as Cataratas correspondem a um fenômeno da natureza; e Itaipu ao resultado da ação humana, mas os dois, um menos e outro mais, não são isentos de uma temporalidade situada com implicações significativas para um modo de vida fronteiriço que tanto objetiva quanto relativiza o estado-nação. Dessa temporalidade situada, porque política e atuante (que não cabe retomar aqui), o dado que trará efeitos determinantes para o objeto deste capítulo é a construção de Itaipu, um grande projeto para geração de energia, erguida pelo Brasil e pelo Paraguai. Imposta por regimes políticos de ditaduras dos dois países, foi planejada como um ente jurídico inédito, mesmo no direito internacional (Ribeiro, 2002, p. 23). Itaipu significou também o aprofundamento das redes entre Brasil e Paraguai, complementado pela construção da Ponte da Amizade.

Figura 1 - Escola na Fronteira Brasil-Paraguai-Argentina

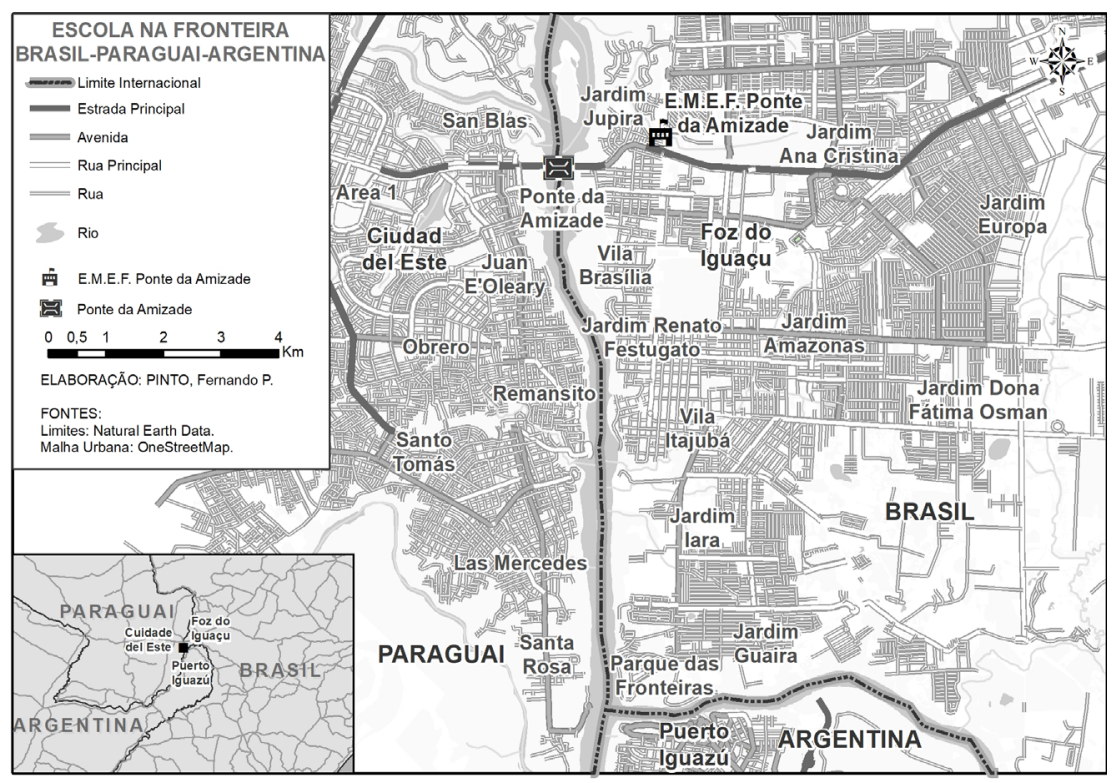

Fonte: elaboração de Fernando P. Pinto (2021) 
Além das estratégias geopolíticas e da necessidade de desenvolvimento econômico do país (Ribeiro, 2002, p.27), a cooperação entre os dois países por meio da Usina significou igualmente abertura dos portos brasileiros ao Paraguai. A consequência foi o crescimento exorbitante do comércio, sustentado por brasileiros de todo o país e viabilizado por pessoas que transportam mercadorias de Ciudad del Este, Paraguai, para Foz do Iguaçu Brasil, fora da cota permitida e/ou em grande quantidade ${ }^{14}$ (BRASIL, 2020). Tais atividades de contrabando e descaminho são crimes contra o estado e temas comuns em etnografias sobre fronteiras situadas em diferentes países, sobretudo a partir do século XIX (Roitman 1999, 2004, 2006; Donnan; Wilson, 1999; Cardin, 2011; Dorfman, 2013, 2015, 2017; Renoldi, 2015; Silva, 2018). Uma das racionalizações comuns para essa atividade de transporte de mercadorias, em Foz do Iguaçu, é de que se trata de um trabalho legítimo, pois as pessoas são "contratadas" informalmente por outras, "patrões", e pagas para "atravessar", "passar" ou puxar as mercadorias. Não são compradores ocasionais e, em geral, desconhecem seus "patrões".

Para estudiosos das fronteiras, esse tipo de racionalização de grupos que nelas vivem está imersa em ambiguidades e depende do que impele esses grupos a atravessá-las e do maior ou menor rigor pelo qual são controladas (Donnan; Wilson, 1999). O controle, em seu efeito, faz dos habitantes locais um coletivo a se constituir em um "nós" (brasileiros) - para outras nacionalidades (Silva, 2020) - e a se multiplicar em "outros" no interior da própria nacionalidade (fronteiriços versus nacionais/regionais). Institui igualmente um "eles" (fora da lei) para as autoridades de fiscalização e controle, quando a travessia é feita por grupos cujo trabalho é mantido por atividades tipificadas como ilegais. Em outros termos, na fronteira, as contingências que tornam problemático o ilegal são igualmente constitutivas daquilo que cria o ilegal no momento da travessia. Instituída pela legalidade, a ilegalidade pode ser um

14 Em 2019, foram introduzidos, do total de apreensões, 1 terço de cigarros falsificados ou trazidos irregularmente; os outros itens em quantidades significativas foram eletroeletrônico, itens de vestuário e óculos de sol. Disponível em: http://receita.economia.gov.br/noticias/ ascom/2020/abril/receita-federal-apreende-r-765-milhoes-em-mercadorias-no-1o-trimestre. Acesso em: 12 de maio. 2020. 
elemento positivo no funcionamento social, pois os dispositivos legislativos têm espaços nos quais a lei pode ser violada ou ignorada, como sugeriu Foucault (1994).

É no contexto das injunções entre a legitimidade e a ilegalidade que enfoco as tensões coconstitutivas do Estado-Nação na Escola: os alunos são filhos ou dependentes dos adultos que vivem das atividades de transporte de mercadorias no Bairro onde ela se localiza. Eles residem na parte mais baixa da encosta, às margens do rio Paraná, a poucos metros da ponte entre Foz do Iguaçu e Ciudad del Este e local onde chegam os barcos trazendo mercadorias do Paraguai. Por meio dos diversos atores que a compõe, a Escola é inseparável das formas de saber e de modos de vida do bairro e da cidade, bem como está inserida nas tensões entre diferentes lógicas (política, jurídica e educacional) implicadas nos atos do Estado que nela convergem. O Bairro é descrito pelos habitantes de Foz do Iguaçu como perigoso, associado ao crime e ao contrabando, e é também alvo de ações de criminalização por parte de agentes de diferentes órgãos de segurança responsáveis pelo controle na fronteira e pela repressão de atividades ilícitas. Materializando o "eles" - que vivem da "cultura do ilícito ${ }^{15}$ (do ponto de vista dos agentes jurídicos e policiais), e, "perigosos", (do ponto de vista da população local) - constitutivos das atividades ilegais, o uso de denominações como "laranjas" ou "muambeiros" (categorias do senso comum) ou "passeiros" (categoria de autoidentificação) identifica quem transporta as mercadorias.

A maioria do dos alunos vive próxima à "barranca", nas margens do rio Paraná, mas a Escola está situada em uma via importante que liga o centro da cidade a Itaipu e a vários bairros e condomínios. Nela também estudaram os pais dos alunos, como afirmaram vários professores. Por estarem associadas a um lugar do "ilícito", as crianças da escola são descritas em "situação de risco" permanente, isto é, o de se envolverem no contrabando, no tráfico e com más companhias. No Projeto Político Pedagógico (PPP) a população é caracterizada como sendo "de nível socioeconômico baixo com predominância

15 "Cultura do ilícito" é uma expressão frequente entre operadores da Justiça para se referirem às pessoas que vivem do contrabando e do descaminho, seja de mercadorias de consumo, drogas etc. 
de trabalhadores da classe autônoma: pedreiros, mecânicos, diaristas, costureiras, ou de empregados instáveis ("laranjas") (PPP, 2012).

Por causa das atividades dos pais e dos adultos com quem vivem as crianças, o modo de vida fronteiriço é entranhado na escola e cria tensões pelas quais a objetivação do Estado é refeita, radicalizando-a, ou desfeita, relativizando-a. Se, por um lado, a escola é um dos lugares que nos faz cidadãos brasileiros - e a educação é vista como um direito fundamental que integra o ideário da cidadania, como vimos acima - por outro, nela ocorre a cisão entre esse ideal de cidadania e a condição vivida. Isto é, a escola é entendida como um espaço indissociável do modo de vida fronteiriço pelas incessantes sobreposições entre a vida cotidiana (de trabalho rotineiro, ilegal/legítimo), o direito (as pretensões de participação do bem público, como educação), a vida (condição existencial para a sobrevivência) e ilegalidade, no qual os limites entre as fronteiras locais e nacionais são, ao mesmo tempo, deslizantes, dissolvidos e enrijecidos. No espaço físico da escola - onde se encontram jovens, crianças, professores, pais, gestores escolares, representantes judiciais e gestores de políticas públicas governamentais -, emergem as práticas instituídas e instituintes do Estado-Nação, tanto radicalizando como relativizando seus limites. Ou seja, na Escola pode-se observar o Estado em atos e a Nação se (des)fazendo em suas fronteiras.

Elementos analíticos decorrentes da tradição weberiana orientam a observação em contexto e a compreensão dos atos do Estado na Escola. O estado é entendido como aquele que detém o monopólio da violência (Weber, 1999) e da violência simbólica (Bourdieu, 2014) legítimos. Para Weber (1999), o estado afirma com êxito a pretensão de um exercício de poder sobre um território (graças ao monopólio do uso legítimo da violência, visível nos aparatos militares e policiais), exercício de poder simbólico, cristalizado nas bandeiras, monumentos, mapas, rituais como festas cívicas e documentos oficiais e pessoais, mas também nas instituições, representadas por agentes dotados do poder de nomeação e de classificações simbólicas, aos quais são delegados poderes, a exemplo de juízes e professores ${ }^{16}$,

$16 \mathrm{O}$ autor afirma que o professor faz um julgamento autorizado por ter a "seu favor toda a força da ordem social, a força do Estado" (Bourdieu, 2014, p. 47). 
etc. Norbert Elias (1993), como chamou a atenção Bourdieu (2014), associou a esses monopólios o monopólio do imposto concentrado nas mãos de uma administração única em cada país. É a concentração dos recursos saídos dessa taxação que permite garantir, entre outros bens públicos, o monopólio da força militar a qual, por sua vez, permite manter o monopólio do imposto.

As implicações significativas dessas concepções, à primeira vista, parecem ser muito abstratas e distantes do cotidiano escolar, mas se tornam significativas em contexto de fronteira, como o da Escola. Nela esses atos do Estado são objetivados em programas endereçados a todo o território nacional, mas contrapostos dinâmica e ativamente em razão do contexto fronteiriço.

\section{Tensões coconstitutivas do estado-nação na Escola}

Para tornar mais claras as tensões coconstitutivas do estado-nação circunscritas nos modos de existência fronteiriços na Escola, abordo a radicalização e a relativização dos atos do Estado na Escola. Contudo, as tensões que supõem esses atos são inseparáveis das práticas e saberes das crianças, pais e adultos com quem vivem, professores, supervisores, pedagogos e diretora da Escola, mas também de gestores de programas públicos que a atravessam. Inicio evidenciando a radicalização da objetivação do estado-nação por meio de um programa de educação fiscal e dos programas para todo o território nacional. Em seguida, abordo a relativização desses atos do Estado por meio dos relacionamentos e interlocuções desses atores na Escola.

A radicalização do estado-nação instituída pelos regulamentos e normas legais, que ordenam a fiscalização de mercadorias na fronteira entre Ciudad del Este e Foz do Iguaçu, torna ilegal a compra quando o tipo, o valor e a quantidade de mercadorias ultrapassam o que está prescrito nas leis. A Receita Federal é a instituição que concentra e administra o monopólio do imposto (os tributos) no país e exerce o controle nas aduanas para evitar justamente evasão fiscal, como não pagar impostos das mercadorias importadas, além de combater o contrabando e o descaminho. Os confrontos com os atos e os regulamentos do monopólio estatal de arrecadação de imposto não se restringem à vigilância, à fiscalização e ao controle na

\footnotetext{
"Se um professor diz, numa forma eufemística: seu filho é um idiota, isso se torna um julgamento que é preciso levar em conta" (Bourdieu, 2014, p. 47).
} 
aduana. Eles estão também presentes na Escola e são mediados pelo Programa Nacional de Educação Fiscal (Brasil, 2009), atos do Estado (Bourdieu, 2014) incorporados pelos agentes da Receita Federal. Esse Programa, elaborado no Paraná, distribui material pedagógico para professores. Durante a pesquisa, encontrei duas revistas de história infanto-juvenil em quadrinhos a fim de promover a compreensão da função socioeconômica dos tributos (Dell'angelo et al., 2007 e Pinto, s/d). Na sala do $5^{\circ}$ ano, havia uma terceira história em quadrinho, veiculada como "revista educativa" e elaborada pelo Fórum Nacional Contra a Pirataria e a Ilegalidade (FNCP, s/d), desenvolvido pelos representantes da indústria brasileira e da Receita Federal.

Nas três revistas, os enredos e a linguagem dos quadrinhos visavam ensinar o que é e o que significa a arrecadação de imposto, a sonegação, o cupom fiscal e os gastos do governo, bem como enfatizar a importância da fiscalização e do controle. A "revista educativa", sem identificação de autoria, elaborada sob a coordenação do Fórum Nacional contra a Pirataria e a Ilegalidade, é ambientada em Foz do Iguaçu e narra a história do trabalho de fiscalização de Adu e Ana (junção de Aduana), personagens e título da revista. Os dois jovens fiscais, um rapaz e uma moça uniformizados, entram em um ônibus de turistas para verificação de bagagem e, ao encontrarem agrotóxicos com um dos passageiros, encaminha-o para a Polícia Federal. Paralelamente, e mudando o cenário para uma gruta escondida nas rochas atrás das quedas de águas das Cataratas, onde se veem caixas de brinquedos, óculos, telefone etc. amontoados, ocorrem cenas de um diálogo entre personagens irritados, sem nomes, cujo líder é caracterizado por trajes estilizados de um pirata. Na contracapa da revista, há a imagem de outro pirata, com aparência grotesca e repugnante, segurando nas mãos brinquedos, celulares, cds e outros produtos, sob o título: "Não existe pirata bonzinho!” (FNCP, s/d).

Talvez o programa de educação fiscal direcionado às crianças não cause nenhuma surpresa em escolas de outros locais e cidades, mas, sobretudo na escola em questão, se revela como um encontro ao mesmo tempo discrepante e apropriado. Discrepante em razão das atividades juridicamente tipificadas como ilegais exercidas pelos pais e por adultos responsáveis pelas crianças da escola. Apropriado, pois é um ato do Estado direcionado às crianças, coerente 
com a presença das atividades de controle e fiscalização aduaneira da Receita Federal na fronteira.

Além da radicalização das práticas instituídas do estado-nação na Escola pela educação fiscal, há a radicalização instituída pelo ensino da língua oficial e suas tensões (como mostrou Pires Santos, 2004, em outras escolas) e pela ritualização em torno dos símbolos nacionais, mais óbvias, sobre as quais não me deterei aqui. Enfoco especificamente os programas de educação de abrangência nacional com os quais o Estado mantém sua base de poder no controle estatístico da população estudantil. As formas desse controle se materializam pelos registros de matrícula de cada aluno, sob a forma de programas para impedir evasão escolar, como o Programa Fica Comigo (FICA) ${ }^{17}$ e o Bolsa Família ${ }^{18}$, e por inúmeros programas de controle capilares, exercidos de forma transversal, como a assistência aos menores, às famílias e às mulheres, preconizados pelo Estatuto da Criança e do Adolescente e a Lei Maria da Penha. Tais programas visavam alcançar diversas formas de participação cidadã, incluindo os direitos diferenciados, acrescidos ao dever do Estado de propiciar a educação. Desse modo ataram a Escola ao controle indireto de implementar diretrizes nacionais orientadas "pelos princípios éticos, políticos e estéticos que visam à formação humana integral e à construção de uma sociedade justa, democrática e inclusiva" (Paraná, 2009) ${ }^{19}$. O papel de integração social e lógica da escola excedeu

17 O Programa Fica Comigo tem como meta, como informa um documento da Secretaria de Estado da Educação/PR, impedir a evasão escolar, pois o acesso à escola e à educação é um direito subjetivo e inalienável. Visa ao pleno desenvolvimento da criança e do adolescente para o exercício da cidadania e qualificação para o trabalho. Disponível em: http://www.gestaoescolar.diaadia.pr.gov.br/arquivos/File/pdf/fica.pdf. Acesso em: 4 jun. 2020.

18 O Bolsa Família surgiu no final de 2003 unificando uma série de programas preexistentes, inspirado pelo programa de renda mínima vinculado à educação, o Bolsa Escola. O Bolsa Família deve atender a famílias cuja renda familiar per capita seja inferior a $\mathrm{R} \$ 60$ mensais e famílias de gestantes, nutrizes, crianças e adolescentes de até 15 anos cuja renda per capita seja inferior a $R \$ 120$ (valores de outubro de 2006). Foi criado por medida provisória, posteriormente convertida em lei.

19 Mais informações podem ser consultadas em Base Nacional Comum. Disponível em: http://basenacionalcomum.mec.gov.br/abase/\#apresentacao. 
ainda mais o ideário de formar o cidadão, sendo ampliado, nessas diretrizes, para uma formação visando atender a competitividade de novas demandas econômicas. Expressa na Constituição de 1988, a preocupação com a "qualidade” do ensino (Chirinéa; Brandão, 2015) passou a ser objeto do poder público.

A qualidade tornou-se uma palavra-chave em atos do Estado, abarcando todo o ensino nacional, e viabilizada por programas de avaliação da educação, a exemplo do Ideb, (Índice de Desenvolvimento da Educação Básica), sistema de indicadores do MEC (Ministério da Educação) e outros atos de transferência de renda, também de alcance nacional, como o programa Bolsa Família. Tais programas são táticas gerais da gestão pública que Foucault denominou governamentalidade $e^{20}$, constituída por níveis diferenciados do poder público, compondo uma rede de instituições articuladas por cálculos, análises e procedimentos para o gerenciamento dos serviços e dos benefícios, cujos mecanismos de controle e de regulação do Estado são endereçados à população escolar e a suas famílias em todo o país. Nos dois programas (o sistema de avaliação e o Bolsa Família), a gestão pública vincula o nível nacional ao municipal (pela organização do ensino), instituindo e objetivando o estado-nação na Escola pela mensuração da qualidade da educação e pela condicionalidade da frequência dos alunos para a manutenção do Bolsa Família.

No primeiro programa, o objetivo é de monitorar e mensurar, nacionalmente, habilidades cognitivas dos estudantes em conteúdos pertinentes às áreas de Língua Portuguesa e Matemática no ensino fundamental. No segundo, o Bolsa Família, de transferência mensal de renda, a seleção dos beneficiários é, em geral, realizada pelos órgãos municipais de assistência social, ficando a gerência do programa a cargo do Ministério da Saúde. Como se observa, a Escola (como qualquer outra no país) é o ponto de convergência da gestão do Estado ao articular educação, saúde e até mesmo a segurança, essa última atravessando a Escola pelos dispositivos jurídicos para a criança e os

20 "Por 'governamentalidade' entendo o conjunto constituído por instituições, procedimentos, análises e reflexões, cálculos e táticas que permitem exercer essa forma de poder bem específica, ainda que complexa, e tem por alvo principal a população.” (Foucault, 2004a , p. 111-112). Também é um tipo 'governo' sobre a soberania e exercício do poder disciplinar em instituições específicas. 
adolescentes e estabelecida quando há necessidade de o conselho tutelar interferir para assegurar a frequência escolar. Isto é, exercer o controle e a vigilância por um mandato do poder central, legítimo e autorizado. O programa exige que as crianças estejam presentes em 85\% das aulas e instituiu um sistema de acompanhamento que é alimentado pelos municípios e transmitido ao governo federal, a fim de que se apliquem advertências e sanções no caso de algum descumprimento das normas. Assim também é o recebimento do Bolsa Família ao ser condicionado a contrapartidas de frequência à escola, de vacinação de crianças e de acompanhamento pré e pós-natal de gestantes e nutrizes -, de acordo com a composição das famílias beneficiárias.

Em relação à obrigatoriedade do "ensino de qualidade" na Escola, os agentes escolares (diretora, supervisora, pedagogos e professores) encarnam a autoridade simbólica explicitamente pela obediência ao mandato que vem da força instituída do Estado. Não só encarnam, mas se engajam ativamente, cumprindo as atividades de ensino exigidas e redobrando os esforços para aprendizagem dos alunos. Em 2017, como contou uma professora durante uma conversa, os índices do Ideb haviam melhorado, mas, nos anos anteriores, eram insuficientes. Para contornar essa dificuldade, em 2018, os professores fizeram dois simulados do Ideb, "um no começo do ano pra avaliar como tá o nível da escola nos quintos anos, nas outras séries também, e a última agora pra saber se a escola evoluiu, então foi feito um trabalho com as crianças pra superar o que tava defasado" (professora Marlene). Antes dos simulados, ministram aulas específicas e aplicação de testes relativos aos conteúdos solicitados na avaliação do Ideb. Devido aos baixos índices obtidos na avaliação, a escola participava do programa Mais Educação ${ }^{21}$,

21 O Programa Mais Educação, criado pela Portaria Interministerial $\mathrm{n}^{\circ}$ 17/2007 e regulamentado pelo Decreto 7.083/10, constitui-se como estratégia do Ministério da Educação para indução da construção da agenda de educação integral nas redes estaduais e municipais de ensino. Essa agenda propõe ampliar a jornada escolar nas escolas públicas para, no mínimo, 7 horas diárias, por meio de atividades optativas, nos macrocampos: acompanhamento pedagógico; educação ambiental; esporte e lazer; direitos humanos em educação; cultura e artes; cultura digital; promoção da saúde; comunicação e uso de mídias; investigação no 
[...] que a princípio era pra ser em horário integral, mas como as escolas não têm estrutura pra atender aluno integral, então os alunos vêm no contraturno pra fazer uma aula de música. A cada ano as oficinas trocam, nós tínhamos balé, depois dança, agora este ano nós temos a música, que o rapaz tá com um novo instrumento, ensinando as crianças, tem o português, tem a matemática, como se fossem as oficinas, também pra ajudar as crianças, é mais lúdico, com jogo, um pouco diferenciado. (professora Marlene).

Cabe à escola, assim, propiciar, por todos os meios, uma formação que atenda aos critérios de avaliação da educação nacional.

A intensificação das atividades dos professores, da supervisora, da secretaria e da diretora da escola "pra saber se a escola evoluiu" e fazer um "trabalho com as crianças pra superar o que tava defasado" explicita o inexprimível de uma intersecção que os agentes escolares mantêm lúcida e resistentemente: a de cumprir exigências contraditórias - a dos programas nacionais incorporados na radicalização dos limites do Estado-Nação (respondendo aos seus diversos controles) e o dos efeitos do modo de existência fronteiriço no cotidiano da Escola, que o relativizam, como mostro em seguida. Longe de produzir conflitos abertos com a gestão dos programas nacionais e produzir tensões em suas condutas profissionais, essas exigências contraditórias são vividas cotidiana e duradouramente por professores, pedagogos, supervisores e diretores na Escola. Sem deixar de responder aos controles capilares que chegam à instituição, os professores passam a ensinar os conteúdos escolares solicitados nos testes nacionais, além de treinarem os alunos para realização do exame. Somam-se aí os procedimentos de ressignificação das avaliações externas, ou seja, a adaptação do ambiente escolar e dos conteúdos curriculares, a fim de demonstrar o suposto nível de qualidade.

campo das ciências da natureza e educação econômica. Disponível em: http://portal.mec.gov.br/component/tags/tag/32787-mais-educacao? start $=100$. Acesso em: 13 maio. 2020. 
Os professores, além de buscar propiciar condições para a avaliação nacional, mantêm a dedicação e o esforço para manter a aprendizagem, a assiduidade e o intenso comprometimento para que as crianças concluam o ensino fundamental, razão de ser do trabalho na Escola, afetado diretamente pelo modo de vida fronteiriço. Primeiro, eles não ocultam aquilo que torna para eles paradoxal a tarefa de educar: mantêm as disposições de acatar, sem julgamento moral, o entendimento e as práticas que crianças, pais e adultos têm como legítimas/ilegais, com a pretensão de fazer do acesso escolar um caminho para outras posições sociais ou simplesmente concluí-lo no nível fundamental. Segundo, sem refutar o duplo compromisso imposto por essas exigências contrárias, interpretam-nas e as aceitam em sua coexistência; sobretudo porque o comprometimento, primeiro e permanente (embora não explicitado nesses termos), é com as interações singulares estabelecidas com um bairro onde "todo mundo é ilegal" (professora Eliza), expressão que identifica pais e adultos das crianças da Escola.

Foi esse o contexto que emergiu no momento da conversa com uma professora, Edilene, dizendo que a escola não é neutra e nem um mundo à parte. Em contexto de injunções de atividades ilegais rotineiras com as práticas da cidade, o lugar da Escola em relação aos moradores do Bairro seria análogo, segundo ela, ao da ONU porque, sendo parte indivisa do contexto, é mediadora dos relacionamentos entre as crianças, adultos e professores. Outros professores expressam esse papel da escola como um ponto de referência importante para alunos, pais e moradores da "comunidade" (expressão da professora Eliza), que a procuram como fonte de obtenção de informação para acesso a serviços de saúde, documentação e outros serviços na cidade. Os professores veem o significado da sua atuação na Escola, para além do ensino, como "acolhimento", "proteção" e "defesa” porque "se você não aceita o modo de vida dos adultos, puxar contrabando... indiretamente não acolhe a criança” (professora Beatriz).

Entre a Escola e o singular modo de vida fronteiriço dos adultos e as crianças, os professores e os supervisores se veem como "elos de ligação". Acolhimento é uma categoria definidora da relação dos agentes escolares (diretora, supervisores, pedagogos, professores) com as crianças e se objetiva em expressões como "acom- 
panhar de perto, vivendo os dramas" das crianças, que trazem o dia a dia da vida dos adultos com quem vivem no Bairro. Nessas interações, os "dramas" vividos e trazidos pelas crianças são acolhidos pelos agentes da escola, mas nunca revelados durante nossa conversa. Os professores falam daquilo que as crianças lhes contam de modo vago e impreciso, mencionando as perdas (de mercadorias), as dificuldades financeiras, a turbulência da intervenção e perseguição policial na "comunidade", as noites mal dormidas e a carência afetiva das crianças. Enfrentando esses "dramas", uma professora expressa as exigências contrárias feitas aos agentes da escola, de acompanhar os índices de avaliação, que ela "não concorda", dada a situação em que vivem as crianças. Ela se questiona a respeito da relação entre as condições socio-econômicas e a aprendizagem, resiste à ideia do fracasso escolar medido por esses parâmetros como resultante da privação (econômica, social e afetiva) ao mesmo tempo em que assume uma disposição de persistir, sob todas as circunstâncias, no ensino.

Como categoria definidora da relação dos professores com as crianças, acolhimento é dar um atendimento diferenciado. Exige qualidades especiais para adaptar ao contexto escolar: "dar atenção", ser "solidários" e se "identificar" com as crianças e com a "comunidade". Tais qualidades são comuns aos professores mais antigos, que estão na Escola há mais tempo e são exigidas aos professores recém-chegados. Elas materializam uma forma de comunicação (nas relações entre diretora, professores, supervisores, adultos e crianças do Bairro) feita de alusões, subterfúgios, atenção ao duplo sentido das conversas, no controle daquilo que se diz e se escuta, mas também na capacidade de calar-se ${ }^{22}$. Essa forma de comunicação está na relutância em apresentar os moradores do Bairro, optando por apresentá-los, ao lado de várias ocupações que não exigem qualificação, como "autônomos" ou "empregados instáveis" ("laranjas").

Congruente com essas qualidades, o ideal a ser atingido como professora é jamais "querer alcançar a perfeição" (professo-

22 Tal forma de comunicação é parte de uma circularidade de alteridades, mais ampla e própria da cidade, como mostramos no artigo Políticas do segredo: incursões etnográficas no campo da (i)legalidade, em Silva e Campos (2018). 
ra Beatriz), porque é necessário “ter jogo de cintura” para articular as exigências institucionais da Escola às necessidades trazidas pelas crianças em razão do modo de vida fronteiriço. O que se espera dos professores é amparar e sustentar as crianças em suas necessidades singulares, de modo a mantê-las na escola.

Por isso, a diretora, os supervisores, os pedagogos e os professores assumem outra atividade complementar ao acolhimento, que é o "resgate", categoria que significa recuperar, por meio de todos os esforços, as crianças que deixam de frequentar as aulas, mas também parece se remeter a significados menos tangíveis de retirá-las de uma situação de perigo, dano ou deriva. Os professores ou a diretora "vão atrás da criança na comunidade", falam "diretamente com a família, que nem essa mãe que está esperando aí, é porque eu liguei, nós ligamos pra mãe vir conversar sobre falta" (professora Marlene). Quis saber por que deixam de ir à escola e a supervisora respondeu: "tem uns que já estão no mundo, já tão nesse mundo deles de passar, de vender. A gente não consegue resgatar mais, a gente perde mesmo", perdi sete alunos, não consegui”. Essa professora falava de crianças com oito, nove, dez anos de idade que "desistiram" da escola, por ela considerada uma derrota pessoal e inapelável. A frequência, ou manter as crianças na escola, é um objetivo tão importante quanto dar formação. "A gente quase busca no laço. É que a gente não sabe onde que ele tá, mas quando sabe, a gente vai lá, busca, desce lá na favela, conversa com eles" (professora Marlene).

Durante a conversa com a professora Marlene, ela enfatiza que a preocupação com a permanência das crianças na Escola é que:

[...] a criança precisa progredir. Tem criança que tá indo bem na escola, aprende tudo e começa a faltar. Daí como fazer? Vai reprovar a criança por causa da falta? Nós não podemos. Evasão? Primeiro nós, na escola, fazemos essa parte de resgatar a criança, liga, manda bilhete, e quando a gente não consegue, aí nós encaminhamos pro conselho. Aí faz a ficha, leva pra secretaria, e a secretaria vai fazer o trabalho de resgate também independente de bolsa família ou não. Porque 
o bolsa família é pra eles, então eles sabem que tendo o bolsa família, os próprios pais sabem que não pode faltar. Mas tem crianças que faltam igual e a gente tem que ficar indo atrás, porque nós não podemos deixar essas crianças não fazer nada. Cada um tem que fazer sua parte." (professora Marlene).

Os professores também conversam com as crianças sem querer "entrar na vida particular", "se intrometer de dar conselho como escola". Citando o exemplo de um aluno, a professora disse: "Renato, você é inteligente, termina pelo menos o quinto ano, porque mais pra frente, você vai precisar do seu estudo. De repente agora não, mas e depois? Não se envolva com coisa errada...”. Ela continuou dizendo que o encontrou fora da Escola e falou para voltar, terminar o quinto ano porque faltava pouco, e ele não foi. Ela diz que tenta avaliar alunos "no básico pra tentar não deixar ele desistir da escola e terminar um ciclo (...) A gente dá conselho pra eles, todos alunos, mas eles não veem isso agora. Igual com filho, a gente tá falando, mas eles não entendem porque a mãe tá falando isso" (professora Marlene).

"Acolher as crianças" quando estão na escola e "resgatá-las" quando deixam de ir para a Escola expressam as contradições entre o desejável e o possível das práticas escolares dos professores e de suas relações com alunos, um empenho duplo e sem tréguas para articular demandas paradoxais entre as exigências nacionais e os efeitos trazidos na Escola pelo modo de vida fronteiriço. As imagens associadas a um "resgate" de crianças perdidas para as "coisas erradas", para o "mundo deles de passar e vender" e para quaisquer formas de vida fora de escola, bem como as imagens ligadas ao acolhimento que, resumindo é a aceitação incondicional e não valorativa dos "dramas" que as crianças "trazem no dia a dia", nos diz de uma prática ambivalente e engajada dos professores, igualmente desdobrada no tempo experimentado coletivamente na escola.

Nesse espaço social compartilhado entre todos, a distribuição das crianças por idades nos horários de funcionamento escolar depende do ritmo das atividades dos pais e dos adultos, bem 
como define, de certa maneira, o ritmo das atividades pedagógicas. O professor tem de "saber dosar", "entrar no ritmo deles", "ter formas diferentes de ensinar e aprender e se adaptar ao contexto social e educativo".

É esse ritmo que ordena o horário de funcionamento da Escola. O período matutino é reservado aos alunos maiores, de terceiro ao quinto ano, porque podem ir à escola sozinhos. Os menores, do pré-escolar, da classe especial, do primeiro e segundo anos, estudam no período vespertino, porque necessitam de acompanhantes para organizar a rotina diária e levá-los até a escola. Segundo a diretora, essa foi a estratégia adotada para diminuir a evasão escolar. Os pais e/ou responsáveis trabalham nos períodos da tarde e da noite. Quando a escola atendia os menores no período da manhã, o número de faltosos tornouse insustentável; as crianças constantemente faltavam às aulas, porque os pais estavam dormindo, descansando do trabalho, na maioria das vezes, noturno. O trabalho dos pais e/ou responsáveis começa a partir das 16 horas, quando fecha o comércio do Paraguai, e o trânsito torna-se mais intenso, devido à saída do Bairro de vans, carros e camionetes com mercadorias vindas do Paraguai.

Como se observa, longe de qualquer resignação e inércia, as práticas e os saberes compartilhados por todos na Escola aprofundam as tensões nas articulações instituídas e instituintes do estado-nação, (re)fazendo e demarcando seus limites, tanto radicalizado por meios dos programas nacionais, quanto relativizado pela distintividade do modo de existência fronteiriço.

\section{Educar na fronteira}

Educar na fronteira, mais do que educar para a fronteira, pode ser tomado como uma expressão sintética da reflexão sobre a Escola em contexto a que me propus neste capítulo. Espero ter mostrado que os limites fronteiriços, a Escola e o estado-nação não são meros espaços físicos. Ou melhor, como espaços, físicos e sociais, são objetivações coconstitutivas da experiência coletiva de grupos e pessoas intrinsecamente articuladas entre si. Esse fundamento é que permitiu sustentar o argumento de que o estado-nação se objetiva na educação formal e pública em geral, mas, 
nas escolas localizadas em fronteiras geopolíticas, essa objetivação tende a ser diluída. As articulações e os limites do estado-nação são constantemente (re)feitos e (des)feitos na experiência e nos próprios termos dos envolvidos direta ou diretamente envolvidos na escola (nas relações entre diferentes crianças, professores, pais, adultos e outros gestores dos serviços públicos). Igualmente podem afetar a legitimidade do estado, dele se distanciando e se aproximando, seja relativizando ou radicalizando suas fronteiras.

Entre as práticas e os saberes de todos os envolvidos, as ações dos professores são as que mais atualizam as inevitáveis contradições do cotidiano escolar fronteiriço, visíveis nos esforços para atender demandas paradoxais do ensino e manifestas com lucidez por eles. Os professores participam ativamente do saber compartilhado por todos, inclusive pelas crianças, como mostrei em publicações anteriores (Silva, 2015; Silva; Godoy, 2016). Estar mergulhado em contradições como as dos professores da Escola é, para Bourdieu (1996), algo comum a outros "trabalhadores sociais" como assistentes sociais professores e magistrados. Segundo o autor, eles constituem a mão esquerda do Estado, um conjunto de agentes que, no interior do Estado, carregam indícios das lutas sociais do passado em contraposição aos burocratas. Na Escola, os professores, a diretora, os pedagogos e os supervisores são a mão esquerda do Estado, cuja mão direita, daqueles que implementam políticas nacionais, não quer saber o que a mão esquerda faz, como afirmou Bourdieu (1996). É nessa assincronia que, por meio dos atores da Escola, os atos do estado-nação são instituídos na vida das crianças, dos pais e dos adultos que trabalham transportando mercadorias na fronteira e, ao mesmo tempo, diluídos nas tensões coconstitutivas desse mesmo estado-nação pelas injunções entre a legitimidade e a ilegalidade, inseparáveis da Escola. 


\section{Referências}

ANDERSON, B. Comunidades Imaginadas. São Paulo: Companhia das Letras, 2008.

BENEDICT, Ruth. O Crisântemo e a Espada, São Paulo: Perspectiva, 1972.

BOURDIEU, Pierre. "A produção e a reprodução da língua legítima”. In: A economia das trocas linguísticas. São Paulo: Edusp, 1996 p. 29-52.

BOURDIEU, Pierre. Contrafogos: táticas para enfrentar a invasão neoliberal. Rio de Janeiro: Jorge Zahar Ed., 1998.

BOURDIEU, P. Escritos da Educação. Petrópolis, RJ: Vozes, 2007.

BOURDIEU, Pierre. Sobre o Estado: cursos no Collége de France (1989/92). São Paulo: Companhia das Letras, 2014.

BRASIL. Ministério da Fazenda. Escola de Administração Fazendária. Programa Nacional de Educação Fiscal - PNEF. Brasília: ESAF, 2009. vols 1, 2, 3 e 4.

BRASIL. Ministério da Economia: Receita Federal. Assessoria de Comunicação Institucional. Receita Federal apreende 765 milhões em mercadorias no 1o semestre, 2020. Disponível em: <http://receita.economia.gov.br/noticias/ascom/2020/abril/receita-federal-apreende-r-765-milhoes-em-mercadorias-no-1o-trimestre.> Acesso em: 12 maio. 2020.

CARDIN, Eric G. Laranjas e sacoleiros na tríplice fronteira: um estudo da precarização do trabalho no capitalismo contemporâneo. Cascavel: EDUNIOESTE, 2011. 136 p.

CHIRINÉA, Andréia; BRANDÃO, C. da Fonseca. O IDEB como política de regulação do Estado e legitimação da qualidade: em busca de significados. Ensaio: aval. pol. públ. Educ., Rio de Janeiro, v. 23, n. 87, p. 461-484, abr./jun. 2015.

DELL'ANGELO, Carlos, Souza M.H., Nascentes, Nilce C. O. e Santos, Rosa F. De olho na cidade. Programa de Educação Fiscal do Paraná: 2007.

DEWEY, John. A concepção democrática de educação. In: John Dewey. WESTBROOK, R.; DEWEY, J.; TEIXEIRA A., (org.). - Recife: Fundação Joaquim Nabuco, Editora Massangana, 2010. DONNAN, Hastings; WILSON, Thomas M. Frontiers of identity, nation and state. New York: Oxford, 1999. 
DORFMAN, Adriana; França, Arthur B. Colen. "Panorama, percurso, e possível agenda para os estudos fronteiriços brasileiros”. In: Dorfmann, Adriana. (Org.) Anuário Unbral das fronteiras brasileiras 2014. Porto Alegre: Editora Letra 1; Instituto de Geociências/ UFRGS, 2015. pp 13-35.

DORFMAN Adriana, FRANÇA Arthur Borba Colen \& FRANÇA Rafael Francisco. Political Commodities and Sovereignty Management: Cigarette Smuggling across Brazil's Southern Borders, Geopolitics, 2017.

DORFMAN, Adriana; FRANÇA, Arthur Borba Colen; ROCHA, Rafael Port da. Dinâmicas temáticas, disciplinares, espaciais e temporais dos Estudos Fronteiriços no Brasil: teses e dissertações (20002014). Anuário Unbral das fronteiras brasileiras. Vol. 3 (2017), p. 11-50, Apêndice p. 153-160. Ver http://hdl.handle.net/10183/170022. DORFMAN, Adriana. A condição fronteiriça diante da securitização das fronteiras do Brasil. In: D. Nascimento; J. P. Rebelo. Fronteiras em perspectiva comparada e temas de defesa da Amazônia. Belém: EDUFPA, 2013.

DORFMAN, Adriana. Pequenas fontes submersas: interpretações geográficas e antropológicas de literaturas de contrabando. Bol. Mus. Para. Emílio Goeldi. Ciências Humanas, Belém, v. 3, n. 1, jan.-abr. 2008, p. 93-114.

DUMONT, Louis. O individualismo: uma perspectiva da ideologia moderna. Rio de Janeiro: Rocco, 1995. 283 p.

DURKHEIM, Émile. A educação, sua natureza e função. In: DURKHEIM, Émile. Educação e Sociologia, São Paulo: Melhoramentos, 1978, pp. 25-44.

ELIAS, Norbert. O processo civilizador: formação do Estado e Civilização. Rio de Janeiro: Jorge Zahar Ed. Jorge Zahar 1993.

EMER, Ivo Oss. Desenvolvimento histórico do Oeste do Paraná e a construção da Escola. Dissertação submetida como requisito parcial para a obtenção do grau de mestre em Educação. Fundação Getúlio Vargas: Rio de Janeiro, 1991.

FLORES, Olga V. O Programa Escola Intercultural Bilíngue De Fronteira: Um Olhar Para Novas Políticas Linguísticas. 2012. Dissertação (Mestrado em Letras) - UNIOESTE, Cascavel. 
FÓRUM NACIONAL CONTRA A PIRATARIA E A ILEGALIDADE FNCP. Adu e Ana: encarando a pirataria e o contrabando. Revista Educativa, n.1.s/d.

FOUCAULT, Michel. 1998. Vigiar e punir: nascimento da prisão. Petrópolis: Vozes, 1984.

FOUCAULT, Michel. Dits et écrits. Paris: Gallimar, 1994.

GELLNER, E. Nações e nacionalismo. Lisboa: Gradiva, 1993.

GODOY, Marisa E. Cassaro. Ser criança em uma escola pública do lado brasileiro da fronteira Brasil/Paraguai: dos feixes atando pontes. 2015. Dissertação (Mestrado em Sociedade, Cultura e Fronteiras) - UNIOESTE, Foz do Iguaçu.

HOBSBAWM, Eric J. Nações e nacionalismo desde 1780. Rio de Janeiro: Paz e Terra, 1990.

HOBSBAWM, E. J. Introdução e A produção em massa de tradições. In: HOBSBAWM, E. J. E RANGER, T. A invenção das tradições. Rio de Janeiro, Paz e Terra, 1997.

MASSCHELEIN, Jan e SIMONS, Maarten. 2014. Em defesa da escola: uma questão pública. Trad. Cristina Antunes. BH: Autêntica.

MAXWELL, Kenneth. Marquês de Pombal: paradoxo do Iluminismo. Rio de Janeiro: Paz e Terra, 1996.

MEAD, Margaret. Sexo e Temperamento. São Paulo: Perspectiva, 2017.

MEDEIROS, Marcelo; BRITTO, Tatiana; SOARES, Fábio. Transferência de renda no Brasil. Novos estud. - CEBRAP, São Paulo, n. 79, p. 5-21, Nov. 2007. Disponível em: <https://doi.org/10.1590/S010133002007000300001> Acesso em: 11 maio. 2020.

PAIVA, Aline C. Políticas educacionais para a diversidade e escolas nas fronteiras: o caso de Foz do Iguaçu na fronteira com a Argentina e Paraguai. 2016. Dissertação (Mestrado em Sociedade, Cultura e Fronteiras) - UNIOESTE, Foz do Iguaçu.

PARANÁ (Estado). Secretaria de Estado de Educação. Programa FICA Comigo : enfrentamento à evasão escolar / Secretaria de Estado da Educação. - Curitiba : SEED - Pr., 2009. - 40 p. Acesso em 4 jun 2020.

PEIRANO, Mariza. A teoria vivida e outros ensaios de antropologia. Rio de Janeiro: Jorge Zahar Editor, 2006. 197 p. 
PINTO, Ziraldo Alves. Que nem gente grande. Programa de Educação Fiscal do Paraná: s/d.

PIRES SANTOS, M. E. O cenário multilíngue/multidialetal/multicultural de fronteira e o processo identitário "brasiguaio" na escola e no entorno social. 2004. Tese (Doutorado em Linguística Aplicada) - Instituto dos Estudos da Linguagem, UNICAMP, Campinas.

PROJETO POLÍTICO PEDAGÓGICO - PPP. Escola Municipal Ponte da Amizade. Educação Infantil e Ensino Fundamental. Foz do Iguaçu, 2012.

QUADROS, Claudemir (org.). Uma gota amarga: itinerários da nacionalização do ensino no Brasil. Santa Maria: UFSM, 2014.

RENOLDI, Brígida Estados posibles: travesías, ilegalismos y controles en la Triple Frontera, Etnográfica [Online], vol. 19 (3) | 2015. Ver http://etnografica.revues.org/4049

RIBEIRO, Maria de Fátima B. Memórias do concreto: vozes na construção de Itaipu. Cascavel: Edunioeste, 2002. 116 p.

ROITMAN, J. Le Pouvoir n'est pas souverain: nouvelles autorites regulatrices et transformations des Etats dans le Bassin du Lac Tchad. In: La privatisation des Etats; Paris: Karthala,1999pp 163-196.

ROITMAN, J. Les recompositions du bassin du lac Tchad. Politique africaine, 94(2), 7-22. 2004. Ver https://doi.org/10.3917/polaf.094.0007.

ROITMAN, Janet. The Ethics of Illegality in the Chad Basin (pdf) in Jean Comaroff and John Comaroff, dirs. Law and Disorder in the Postcolony, University of Chicago Press, 2006.

SAID, Edward W. Cultura e imperialismo. São Paulo, Companhia das Letras, 2011.

SEYFERTH, Giralda. A assimilação dos imigrantes como questão nacional. Mana, Rio de Janeiro, v. 3, n. 1, p. 95-131, Apr. 1997. Ver http://dx.doi.org/10.1590/S0104-93131997000100004.

SILVA, Regina Coeli Machado e. "Vidas, nações e estados se fazendo nas fronteiras entre Brasil, Paraguai e Argentina”. In: Ideação. Revista do Centro de Educação, Letras e Saúde. vol. 15. n. 2. Edunioeste/ Cascavel, 2013. pp 10-32.

SILVA, Regina Coeli Machado e. O Estado-Nação se (des)fazendo no cotidiano vivido em uma escola na Fronteira Brasil, Argentina e Paraguai. IV Enadir (Encontro Nacional de Antropologia do 
Direito, GT n.14. Abordagens antropológicas do Estado). Mimeo. 2015. Ver http://www.enadir2015.sinteseeventos.com.br/simposio/ public.

SILVA, Regina Coeli Machado e.; GODOY, Maria Elizabeth C. Tomar cuidado com o que falo: ser criança na escola, ficar e brincar em casa. Revista Latitude, v. 10, n. 2 PPGS/UFAL: 2016. P. 287-319.

SILVA, R. C. Machado e. Como experimentamos e entendemos, do lado brasileiro, as fronteiras com a Argentina e com o Paraguai. Espaço Aberto. Revista do Programa de Pós-graduação em Geografia. V. 10, n.1 UFRJ: Rio de Janeiro de 2020. Ver https://revistas.ufrj.br/ index.php/EspacoAberto/article/view/30145/19452.

SILVA, R. C. Machado e. CAMPOS, Maria J. Políticas do segredo: incursões etnográficas no campo da (i)legalidade fiscal. Revista Ambivalências. V. 6 n.12. UFS, 2018. Ver https://seer.ufs.br/index.php/ Ambivalencias/article/view/10055

SOMMER, Doris. Ficções de fundação: os romances nacionais da América Latina. Belo Horizonte: Editora UFMG, 2004.

SOUZA, Silvana A. Democracia e qualidade: as consequências da ditadura militar ao sistema educacional, na frágil transição democrática brasileira. SER Social, Brasília, v. 17, n. 36, p. 49-67, jan.-jun./2015.

SOUZA, S. A. Educação, trabalho voluntário e 'responsabilidade social'. 1. ed. São Paulo: Xamã Editora, 2013.

SOUZA, S. A. Gestão escolar compartilhada: democracia ou descompromisso? 1. ed. São Paulo: Xamã Editora, 2001. v. 01. 215p.

WEBBER, Maria Aparecida. Estudantes brasileiros de medicina em Presidente Franco (PY): motivações e tensões de um fluxo universitário transfronteiriço . Dissertação (Mestrado) - Universidade Federal do Paraná. Setor de Ciências Humanas, Programa de Pós-Graduação em Antropologia. Curitiba, 2018. Ver https://acervodigital.ufpr.br/bitstream/handle/1884/58251/R\%20-\%20D\%20-\%20 MARIA\%20APARECIDA\%20WEBBER.pdf?sequence=1\&isAllowe$\mathrm{d}=\mathrm{y}$.

WEBER, Max. Os tipos de dominação. In Economia e sociedade: fundamentos da sociologia compreensiva. Brasília: UNB. São Paulo: Imprensa Oficial do Estado de São Paulo, 1999. vol 1. p. 139 a 166. 